\title{
Factors influencing patient satisfaction with dental appearance and treatments they desire to improve aesthetics
}

\author{
Mon Mon Tin-Oo* ${ }^{*}$ Norkhafizah Saddki, Nurhidayati Hassan
}

\begin{abstract}
Background: We assessed factors influencing patients' satisfaction with their dental appearance and the treatments they desired to improve dental aesthetics.

Methods: A cross-sectional study was performed out among 235 adult patients who visited the Hospital Universiti Sains Malaysia dental clinic. A structured, interviewer-guided questionnaire was used to identify patient satisfaction with their general dental appearance, cosmetic elements and desired treatments.

Results: The 235 patients consisted of 70 males (29.8\%) and 165 females (70.2\%), of mean age 31.5 years (SD 13.0). Of these patients, 124 (52.8\%) were not satisfied with their general dental appearance. In addition, 132 patients (56.2\%) were not happy with the color of their teeth, 76 (32.3\%), regarded their teeth were poorly aligned, 62 (26.4\%), as crowded and 56 (23.4\%) protruded. Dissatisfaction with tooth color was significantly higher in female than in male patients (odds ratio [OR] of 1.99 (95\% confidence interval [Cl] 1.13-3.50). Tooth whitening was the treatment most desired by patients (48.1\%). Results of multiple logistic regression analysis showed that patient dissatisfaction with general dental appearance was significantly associated with female gender $(\mathrm{OR}=2.18 ; 95 \% \mathrm{Cl}$ : 1.18-4.03), unhappiness with tooth color $(\mathrm{OR}=3.05 ; 95 \% \mathrm{Cl}$ : 1.74-5.34) and the opinion that their teeth protruded $(\mathrm{OR}=2.91,95 \% \mathrm{Cl}: 1.44-5.91)$.

Conclusions: Most patients in this study were not satisfied with their dental appearance with a greater percentage of females expressing dissatisfaction than males. An age was not associated with satisfaction. Unhappiness with tooth color and feelings of having protruding teeth also had a significant negative influence on patient satisfaction with general dental appearance.
\end{abstract}

\section{Background}

Dental appearance is an important feature in determining the attractiveness of a face, and thus plays a key role in human social interactions. Among the significant factors affecting overall dental appearance are tooth color, shape, and position; quality of restoration; and the general arrangement of the dentition, especially of the anterior teeth [1]. Furthermore, an aesthetically pleasing smile was found to depend on tooth color, size, shape, and position, upper lip position, visibility of teeth and amount of gingival display [2]. Although each factor may be considered individually, all components must act

\footnotetext{
* Correspondence: monmonto@kb.usm.my

School of Dental Sciences, Universiti Sains Malaysia, Health Campus, 16150 Kubang Kerian, Kelantan, Malaysia
}

(c) 2011 Tin-Oo et al; licensee BioMed Central Ltd. This is an Open Access article distributed under the terms of the Creative Commons Attribution License (http://creativecommons.org/licenses/by/2.0), which permits unrestricted use, distribution, and reproduction in any medium, provided the original work is properly cited. together to create a harmonic and symmetric entity that produces the final aesthetic effect [1].

In general, people desire for pearly white teeth. Thus, tooth color is one of the most important factors determining satisfaction with dental appearance [1,3]. Selfsatisfaction with tooth color decreases with increasing severity of discoloration $[4,5]$. White teeth have been positively correlated with high ratings of social competence, intellectual ability, psychological adjustment and relationship status [6]. Alternatively, untreated dental caries, non-aesthetic or discolored anterior teeth restorations and missing anterior teeth usually lead to dissatisfaction with dental appearance [3,7-9]. Furthermore, treatments improving dental aesthetics have been found to increase patient quality of life and psychological status $[10,11]$. 
Malocclusion is a common oral disorder, although treatment needs and demands vary. In some populations, tooth misalignments are not regarded as serious enough to necessitate treatment [12-14], whereas, in other populations, the need for orthodontic treatment may be very high $[15,16]$. There is general agreement that people are motivated to seek orthodontic treatment because of the negative physical, psychological and social impacts of malocclusion, but studies of the effects of malocclusion and its treatment on people's lives have yielded inconsistent results $[17,18]$. These discrepancies may be due to various interpretations of physical, psychological and social impact and lack of standardized methods to measure these quality of life constructs [17].

Currently, cosmetic dentistry has become an important aspect of dentistry. Tooth whitening treatments, anterior teeth restoration, labial veneers crowns, and orthodontic treatment are frequently demanded by patients who interested in improving their dental appearance [3]. We have assessed satisfaction with dental appearance, desired treatments to improve dental appearance, and factors that influence satisfaction with dental appearance among adult patients who attended the dental clinic at the Hospital Universiti Sains Malaysia (HUSM).

\section{Methods}

This cross sectional study was carried out from June 1 , 2009 to January 31, 2010 among patients who attended the HUSM dental clinic. All included patients were newly registered adults $>18$ years old, who had not received any dental treatment within the previous six months, were able to understand the Malay language and have no clear evidence of cognitive disturbances. Sample size was calculated using the formula estimating a single proportion with a requirement for $95 \%$ confidence [19]. The prevalence of dissatisfaction with dental appearance was estimated to be $62.7 \%$ based on the satisfaction with dental aesthetics among adult patients attending a military dental clinic in Tel Aviv, Israel [3]. Considering the available resources, a sample size of 183 was selected with a precision of 0.07 (7\%). To accommodate for a $30 \%$ non-response rate, 238 patients were invited to participate in this study.

A systematic random sampling technique was used to select the study sample. The sampling interval was decided based on the estimated number of eligible patients attending the clinic on a normal outpatient day, with every tenth patient was invited to participate. No possible biases regarding the selection of the study population were anticipated and the samples were representative of the reference population. This study was approved by the Research and Ethics Committee (Human), Universiti Sains Malaysia.
A structured, interviewer guided questionnaire (Table 1) was used for data collection. The questionnaire consisted of questions on socio-demographic items including sex, age, and level of education, as well as questions on each patient's satisfaction with his/her then-current general dental appearance. Patients were also asked about their satisfaction with tooth color, perceived malalignment of teeth (crowding, poorly aligned or protruding), caries in anterior teeth, non-aesthetic anterior tooth color restoration and presence of tooth fracture. In addition, patients were asked to select the aesthetic treatments they wished to undergo, including orthodontic treatment, crowns, tooth whitening, tooth color restorations and partial dentures.

Prior to this study the clarity of the questionnaire was pre-tested on 15 patients who were not involved in the study. Feedback regarding problems understanding and answering the questionnaire was obtained and addressed. Each patient provided written informed consent before participation in this study.

Data were entered and analyzed using the Statistical Package for Social Sciences (SPSS) for Windows software (version 12.0; SPSS Inc, Chicago). Descriptive statistics such as mean and standard deviation (SD) for continuous variables and frequency and percentage for categorical variables were determined. The chi-square test was used to compare the sex, age, education levels of patients who were and were not satisfied with their dental appearance. The level of significance was set at 0.05 .

Factors influencing patient satisfaction with dental appearance were determined at both the univariate and multivariate levels using simple logistic regression analysis and multiple logistic regression analysis, respectively. Variables selected for inclusion in the multiple logistic regression analysis model were selected using the forward stepwise logistic regression method. Following the fit of the preliminary model, the importance of each variable was verified. The interaction terms were checked using the Likelihood Ratio (LR) test. Multicollinearity problems were was identified by the Variance Inflation Factor (VIF) test.

The final model was assessed for fitness using the Hosmer-Lemeshow goodness-of-fit test. The classification tables for sensitivity and specificity as well as the area under the Receiver Operating Characteristic (ROC) curve were also recorded to assess the model fitness. Influential outliers were identified using Cook's distance. Data points above 1.0 were considered as influential outliers.

\section{Results}

The demographic background of the patients and their satisfaction with their dental appearance are shown in 


\section{Table 1 Questionnaire used in the study}

\begin{tabular}{|c|c|c|c|}
\hline \multicolumn{4}{|c|}{ Survey on patient satisfaction with dental appearance and desired treatment to improve aesthetics } \\
\hline \multicolumn{2}{|c|}{ 1. Sex $\square$ Male $\square$ Female } & \multirow[t]{2}{*}{ 2. Age: } & \multirow[t]{2}{*}{ years) } \\
\hline \multicolumn{2}{|c|}{ 3. Education level: $\square$ Primary $\square$ Secondary $\square$ Post secondary $\square$ Tertiary } & & \\
\hline 1. & Are you satisfied with the general appearance of your teeth? & $\square$ Yes & $\square$ No \\
\hline 2. & Are you satisfied with your tooth color? & $\square$ Yes & $\square \mathrm{No}$ \\
\hline 3. & Do you feel your teeth are crowded? & $\square$ Yes & $\square \mathrm{No}$ \\
\hline 4. & Do you feel your teeth are poorly aligned? & $\square$ Yes & $\square \mathrm{No}$ \\
\hline 5. & Do you feel your teeth are protruding? & 口Yes & $\square \mathrm{No}$ \\
\hline 6. & Do you have dental caries in your front teeth? & $\square$ Yes & $\square \mathrm{No}$ \\
\hline 7. & Do you have non-aesthetic fillings in your front teeth? & $\square$ Yes & $\square \mathrm{No}$ \\
\hline 8. & Do you have fractures in your front teeth? & $\square$ Yes & $\square \mathrm{No}$ \\
\hline \multirow[t]{6}{*}{9.} & Do you wish to undergo these treatments to improve the ap & & \\
\hline & a. Orthodontic treatment to realign teeth & $\square$ Yes & $\square \mathrm{No}$ \\
\hline & b. Tooth whitening & $\square$ Yes & $\square$ No \\
\hline & c. Dental crowns & $\square$ Yes & $\square \mathrm{No}$ \\
\hline & d. Tooth coloured fillings & $\square$ Yes & $\square \mathrm{No}$ \\
\hline & e. Dentures & $\square$ Yes & $\square$ No \\
\hline
\end{tabular}

Table 2. Of the 235 patients, (70.2\%) were female. Ages ranged from 18 to 62 years with a mean age of 31.5 years (SD 13.0). We found that (52.8\%) of these patients were not happy with their general dental appearance, with dissatisfaction with tooth color being the most common (56.2\%). In addition, some patients regarded their teeth as poorly aligned (32.3\%), crowded (26.4\%), and protruding (23.4\%). Others reasons for dissatisfaction include self-reported presence of caries (43.4\%), non-aesthetic restorations (30.6\%), and tooth fractures (15.3\%). Patients also answered questions about the treatments they desired to improve their appearance (Table 3). We found that $48.1 \%$ wished to have their teeth whitened, followed by restoration of tooth color (18.3\%), dentures (16.2\%), orthodontic treatment (14.0\%), and dental crowns (11.5\%).

Table 4 shows a comparison between the 111 patients who were and the 124 who were not satisfied with their general dental appearance. We found that satisfaction with dental appearance differed significantly between males and females. In addition, dissatisfaction with tooth color and perception that of having protruding teeth had significant negative impacts on patient satisfaction with general dental appearance. No other dental problem or condition was associated with patient satisfaction with general dental appearance.

Simple logistic regression analysis of factors influencing patient satisfaction with dental appearance found no significant associations between patient satisfaction and age, education level, perception of having crowded and poorly aligned teeth, self-reported dental caries, non-aesthetic restorations, and fractures of the anterior teeth (Table 5). However, dissatisfaction with general dental appearance was significantly associated with female gender $(\mathrm{OR}=$
2.70, 95\% CI: 1.51-4.82), with unhappiness with tooth color (OR $=3.35,95 \% \mathrm{CI}: 2.01-5.92)$ and with regarding their teeth as protruding $(\mathrm{OR}=3.42,95 \% \mathrm{CI}$ : $1.75-6.71)$.

Multivariable logistic regression analysis showed that female gender $(\mathrm{OR}=2.18,95 \% \mathrm{CI}$ : 1.18-4.03), unhappiness with tooth color $(\mathrm{OR}=3.05,95 \% \mathrm{CI}$ : 1.74-5.34) and the opinion who felt that their teeth were protruded (OR $=2.91,95 \%$ CI: 1.44-5.91) were significant independent determinants of patient satisfaction with general appearance (Table 6). Possible two-way interactions between factors were not significant, and there was no multicollinearity problem. The preliminary final model was checked for fitness. The result of HosmerLemeshow goodness-of-fit test was not significant $(p=$ $0.631, \mathrm{df}=4$ ) and the area under the ROC curve was 0.714 , suggesting that the model was fit. The sensitivity and specificity of this model were $64.9 \%$ and $64.5 \%$ respectively. These results indicated that satisfaction with general dental appearance could be predicted correctly in $64.7 \%$ of these patients. When we assessed the contribution of each outlier, we found that none was influential.

Further analyses were performed to evaluate the perceptions of different groups of patients about the color of their teeth. Table 7 shows the distribution of responses by the socio-demographic background (age, sex and education level) between the103 patients who were and the 132 patients who were not satisfied with their tooth color. Results of the chi-square test showed that satisfaction with tooth color differed significantly between male and female patients whereas none of the other background variables was significant. Both simple and multiple logistic regression analyses showed that dissatisfaction with tooth color was significantly higher in female than in males (OR $=1.99 ; 95 \%$ CI: 1.13-3.50). 
Table 2 Background of patients and satisfaction with dental appearance $(n=235)$

\begin{tabular}{|c|c|}
\hline Variables & Frequency (\%) \\
\hline \multicolumn{2}{|l|}{ Age group (years) } \\
\hline$<35$ & $146(62.1)$ \\
\hline $35-54$ & $76(32.3)$ \\
\hline$\geq 55$ & $13(5.5)$ \\
\hline \multicolumn{2}{|l|}{ Sex } \\
\hline Male & $70(29.8)$ \\
\hline Female & $165(70.2)$ \\
\hline \multicolumn{2}{|l|}{ Education } \\
\hline Primary/Secondary & $157(66.8)$ \\
\hline Post secondary/Tertiary & $78(33.2)$ \\
\hline \multicolumn{2}{|c|}{ Satisfied with general dental appearance } \\
\hline No & 124(52.8) \\
\hline Yes & $111(47.2)$ \\
\hline \multicolumn{2}{|l|}{ Dissatisfied with tooth color } \\
\hline No & $103(43.8)$ \\
\hline Yes & $132(56.2)$ \\
\hline \multicolumn{2}{|l|}{ Felt that teeth were crowded } \\
\hline No & $173(73.6)$ \\
\hline Yes & $62(26.4)$ \\
\hline \multicolumn{2}{|c|}{ Felt that teeth were poorly aligned } \\
\hline No & $159(66.7)$ \\
\hline Yes & $76(32.3)$ \\
\hline \multicolumn{2}{|l|}{ Felt that teeth protruded } \\
\hline No & $180(76.6)$ \\
\hline Yes & $55(23.4)$ \\
\hline \multicolumn{2}{|l|}{ Perceived dental caries } \\
\hline No & $133(56.6)$ \\
\hline Yes & $102(43.4)$ \\
\hline \multicolumn{2}{|c|}{ Perceived non-aesthetic restorations } \\
\hline No & $163(69.4)$ \\
\hline Yes & $72(30.6)$ \\
\hline \multicolumn{2}{|l|}{ Perceived fractures } \\
\hline No & $199(84.7)$ \\
\hline Yes & 36 (15.3) \\
\hline
\end{tabular}

\section{Discussion}

Attitudes and perceptions towards dental appearance differ among populations and among individuals in a population [20]. We found that of adults attending the HUSM dental clinic, only $47.2 \%$ were satisfied with the
Table 3 Desired aesthetic dental treatments $(n=235)$

\begin{tabular}{ll}
\hline Variables & Frequency (\%) \\
\hline $\begin{array}{l}\text { Orthodontic treatment } \\
\text { No }\end{array}$ & $202(86.0)$ \\
Yes & $33(14.0)$ \\
Tooth whitening & \\
$\quad$ No & $122(51.9)$ \\
Yes & $113(48.1)$ \\
Dental crown & \\
No & \\
Yes & $208(88.5)$ \\
Tooth color restoration & $27(11.5)$ \\
No & \\
Yes & $192(81.7)$ \\
Denture & $43(18.3)$ \\
No & \\
Yes & \\
\hline
\end{tabular}

appearance of their teeth, a lower percentage than in previous studies of different populations. For example, a study of 1,014 patients at a dental school in Ankara, Turkey found that $(57.3 \%)$ were satisfied with their dental appearance [7] as were $76 \%$ of stratified sample of adults in the United Kingdom [21].

Perception towards dental appearance is determined by cultural factors and individual preferences varying between individuals and cultures and changing over time [1]. In general, older people (age 55 and above) were more likely than younger people to be satisfied with their dental appearance $[7,21]$, suggesting that the appearance of their teeth is not as important to older than to younger individuals [20]. In this study, however, we found that age was not associated with satisfaction with dental appearance suggesting that dental appearance is becoming equally important in both older and younger adults. This is likely due to the strong impact of the media which portray men and women of all ages as needing to look younger and more beautiful. Indeed, a study of 180 people of six different age strata ranging from 13 to 64 years showed that personal satisfaction with tooth color was age-independent [22]. A study in Sweden of two large samples of 8,881 aged 50 years and 8,563 aged 60 years revealed that the majority of respondents in both groups agreed that beautiful and perfect teeth are very important [23]. Another study on elderly aged 73 to 75 year old in Germany also showed that the importance of dental appearance to overall appearance was rated high by the subjects [24].

Tooth color is a critical factor influencing satisfaction with smile appearance [1]. For example a study in the 


\begin{tabular}{|c|c|c|c|c|}
\hline & \multicolumn{2}{|c|}{ Satisfied } & \multirow[t]{2}{*}{$\chi^{2}$ statistics $(\mathrm{df})$} & \multirow[t]{2}{*}{$p$ value } \\
\hline & $\begin{array}{l}\text { Yes (\%) } \\
\mathrm{n}=111\end{array}$ & $\begin{array}{l}\text { No (\%) } \\
n=124\end{array}$ & & \\
\hline \multicolumn{5}{|l|}{ Age group (years) } \\
\hline$<35$ & $68(61.3)$ & $78(62.9)$ & $1.135(2)$ & 0.567 \\
\hline $35-54$ & $35(31.5)$ & $41(33.1)$ & & \\
\hline$\geq 55$ & $8(7.2)$ & $5(4.0)$ & & \\
\hline \multicolumn{5}{|l|}{ Sex } \\
\hline Male & $45(40.5)$ & $25(20.2)$ & $11.631(1)$ & 0.001 \\
\hline Female & $66(59.5)$ & $99(79.8)$ & & \\
\hline \multicolumn{5}{|l|}{ Education } \\
\hline Primary/Secondary & $70(63.1)$ & $87(70.2)$ & $1331(1)$ & 0.249 \\
\hline Post secondary/Tertiary & $41(36.9)$ & $37(29.8)$ & & \\
\hline \multicolumn{5}{|l|}{ Dissatisfied with tooth color } \\
\hline No & $66(59.5)$ & $37(29.8)$ & $20.873(0)$ & $<0.001$ \\
\hline Yes & $45(40.5)$ & $87(70.2)$ & & \\
\hline \multicolumn{5}{|l|}{ Felt that teeth were crowded } \\
\hline No & $84(75.7)$ & $89(71.8)$ & $0.459(1)$ & 0.498 \\
\hline Yes & $27(24.3)$ & $35(28.2)$ & & \\
\hline \multicolumn{5}{|c|}{ Felt that teeth were poorly aligned } \\
\hline No & $80(72.1)$ & $79(63.7)$ & $1.872(1)$ & 0.171 \\
\hline Yes & $31(27.9)$ & $45(36.3)$ & & \\
\hline \multicolumn{5}{|l|}{ Felt that teeth protruded } \\
\hline No & $97(87.4)$ & $83(66.9)$ & $13.666(1)$ & $<0.001$ \\
\hline Yes & $14(12.6)$ & $41(33.1)$ & & \\
\hline \multicolumn{5}{|l|}{ Perceived dental caries } \\
\hline No & $63(56.8)$ & $70(56.6)$ & $0.002(1)$ & 0.962 \\
\hline Yes & $48(43.2)$ & $54(43.5)$ & & \\
\hline \multicolumn{5}{|c|}{ Perceived non-aesthetic restorations } \\
\hline No & $78(70.3)$ & $85(68.5)$ & $0.082(1)$ & 0.775 \\
\hline Yes & $33(29.7)$ & $39(31.5)$ & & \\
\hline \multicolumn{5}{|l|}{ Perceived fractures } \\
\hline No & $94(84.7)$ & $105(84.7)$ & $0.000(1)$ & 0.999 \\
\hline Yes & $17(15.3)$ & $19(15.3)$ & & \\
\hline
\end{tabular}

United Kingdom found that the general public were dissatisfied with relatively mildly discoloured teeth indicating their concern about the color of their teeth [4]. Perception of tooth color is a complex phenomenon that is influenced by many factors including lighting conditions, the optical properties of teeth (translucency, opacity, scattering of light, surface gloss), and the viewer's visual experience [25]. We found that most respondents $(56.2 \%)$ were dissatisfied with the color of their teeth in agreement with studies in populations in other countries $[3,5,7]$. In agreement with previous results, we found that, dissatisfaction with tooth color may be the primary reason for dissatisfaction with dental appearance [3].

The important contribution of tooth color to patients' satisfaction with dental appearance was further highlighted 
Table 5 Factors influencing patients' satisfaction with dental appearance by simple logistic regression analysis

\begin{tabular}{|c|c|c|c|c|}
\hline Variables & $\begin{array}{l}\text { Crude } \\
\text { OR }\end{array}$ & $95 \% \mathrm{Cl}$ & $\begin{array}{l}\text { LR } \chi^{2} \\
(\mathrm{df})^{\mathrm{a}}\end{array}$ & $\begin{array}{l}p \\
\text { value }^{a}\end{array}$ \\
\hline \multicolumn{5}{|l|}{ Age group (years) } \\
\hline$<35$ & 1.00 & - & $1.139(2)$ & 0.566 \\
\hline $35-54$ & 1.02 & $0.59-1.78$ & $0.005(1)^{b}$ & 0.941 \\
\hline$\geq 55$ & 0.55 & $0.17-1.75$ & $1.046(1)^{\mathrm{b}}$ & 0.306 \\
\hline \multicolumn{5}{|l|}{ Sex } \\
\hline Male & 1.00 & - & $11.720(1)$ & 0.001 \\
\hline Female & 2.70 & $1.51-4.82$ & & \\
\hline \multicolumn{5}{|l|}{ Education } \\
\hline Primary/Secondary & 1.00 & - & $1.330(1)$ & 0.249 \\
\hline Post secondary/Tertiary & 0.73 & $0.42-1.25$ & & \\
\hline \multicolumn{5}{|l|}{ Dissatisfied with tooth color } \\
\hline No & 1.00 & - & $21.156(1)$ & $<0.001$ \\
\hline Yes & 3.35 & $2.01-5.92$ & & \\
\hline
\end{tabular}

Felt that teeth were crowded

$\begin{array}{lllll}\text { No } & 1.00 & - & 0.460(1) & 0.498 \\ \text { Yes } & 1.22 & 0.68-2.19 & & \end{array}$

Felt that teeth were poorly aligned

$\begin{array}{lllll}\text { No } & 1.00 & - & 1.881(1) & 0.170 \\ \text { Yes } & 1.47 & 0.85-2.56 & & \end{array}$

Felt that teeth protruded

$\begin{array}{llll}\text { No } & 1.00 & - & 14.217(1)<0.001 \\ \text { Yes } & 3.42 & 1.75-6.71 & \end{array}$

Perceived dental caries

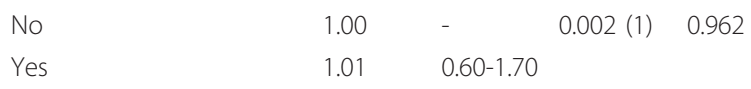

Perceived non-aesthetic restorations

\begin{tabular}{|c|c|c|c|}
\hline No & 1.00 & - & $0.082(1)$ \\
\hline Yes & 1.08 & $0.62-1.89$ & \\
\hline
\end{tabular}

Perceived fractures

$\begin{array}{lllll}\text { No } & 1.00 & - & 0.000(1) & 0.999 \\ \text { Yes } & 1.00 & 0.49-2.04 & & \end{array}$

${ }^{a}$ Likelihood Ratio (LR) test.

${ }^{\mathrm{b}}$ Wald test.

by our finding that tooth whitening was the aesthetic treatment most desired by participants, a finding similar to previous results [3]. In addition a study of 180 female patients in South London [6] showed that whitened teeth were preferred over teeth with original color with the
Table 6 Factors influencing patients' satisfaction with dental appearance by multiple logistic regression analysis

\begin{tabular}{lllll}
\hline Variables & $\begin{array}{l}\text { Adjusted } \\
\text { OR }\end{array}$ & $\mathbf{9 5 \% ~ C l}$ & $\begin{array}{l}\text { LR } \chi^{2} \text { (df) } \\
\text { Sex }\end{array} \quad \begin{array}{l}\boldsymbol{p} \\
\text { value }^{\mathbf{a}}\end{array}$ \\
\hline $\begin{array}{l}\text { Male } \\
\text { Female }\end{array}$ & 1.00 & - & $6.287(1)$ & 0.012 \\
& 2.18 & $1.18-4.03$ & &
\end{tabular}

Satisfied with tooth color

$\begin{array}{llll}\text { No } & 1.00 & - & 15.568(1)<0.001 \\ \text { Yes } & 3.05 & 1.74-5.34 & \end{array}$

Felt that teeth

protruded

\begin{tabular}{lllll} 
No & 1.00 & - & $9.432(1)$ & 0.002 \\
Yes & 2.91 & $1.44-5.91$ & & \\
\hline
\end{tabular}

${ }^{a}$ Likelihood Ratio (LR) test.

former associated with greater attractiveness. In contrast another study in Germany done by Höfel et al. [26] found that perceptions of facial attractiveness were independent of tooth color indicating that satisfaction with dental appearance may not correlate positively with facial attractiveness. This finding underlines the influence of psychosocial attributes on the perception of attractiveness.

Many of the patients in this study reported having dental caries and non-aesthetic restorations in their front teeth, with and some reported having tooth fractures. All of these conditions will undoubtedly affect the appearance of teeth, presumably leading to patient dissatisfaction with general dental appearance. Although our

Table 7 Socio-demographic background of patients who were $(n=103)$ and were not $(n=132)$ satisfied with their tooth colour

\begin{tabular}{|c|c|c|c|c|}
\hline \multirow[t]{2}{*}{ Variables } & \multicolumn{2}{|c|}{ Satisfied } & \multirow{2}{*}{$\begin{array}{l}\chi^{2} \text { statistics } \\
\text { (df) }\end{array}$} & \multirow[t]{2}{*}{$p$ value } \\
\hline & $\begin{array}{l}\text { Yes (\%) } \\
\mathrm{n}=103\end{array}$ & $\begin{array}{l}\text { No }(\%) \\
n=132\end{array}$ & & \\
\hline \multicolumn{5}{|l|}{ Age group (years) } \\
\hline$<35$ & $56(54.4)$ & $90(68.2)$ & $4.698(2)$ & 0.095 \\
\hline $35-54$ & $40(38.8)$ & $36(27.3)$ & & \\
\hline$\geq 55$ & $7(6.8)$ & $6(4.5)$ & & \\
\hline \multicolumn{5}{|l|}{ Sex } \\
\hline Male & $39(37.9)$ & $31(23.5)$ & $5.720(1)$ & 0.017 \\
\hline Female & $64(62.1)$ & $101(76.5)$ & & \\
\hline \multicolumn{5}{|l|}{ Education } \\
\hline Primary/Secondary & $66(64.1)$ & $91(68.9)$ & $0.617(1)$ & 0.432 \\
\hline $\begin{array}{l}\text { Post secondary/ } \\
\text { Tertiary }\end{array}$ & $37(35.9)$ & $41(31.1)$ & & \\
\hline
\end{tabular}


patients in this study were not significantly affected by any of those conditions a previous study [3] reported that patient satisfaction with dental appearance was significantly influenced by self-reported caries in anterior teeth, but not by other conditions. Further, decayed anterior teeth were shown to have negative impact on perceptions of facial attractiveness [6].

Patients with high levels of education were found to be more satisfied with the color of their teeth than individuals with lower academic achievement [5,7] as well as to have a lower preference for white teeth [20]. These findings suggested that the higher self-satisfaction with tooth colour observed in individuals with higher academic achievement may reflect higher self-esteem [5,7]. Among our patients the education level did not have impact on satisfaction with tooth color or general dental appearance.

It is a commonly thought that women are more interested in their appearance than men. Indeed, female patients were found to be more concerned with their dental appearance than males [20] as well as to be more critical in judging their dental appearance [24]. Similar to previous results [3] we found that women expressed greater dissatisfaction with dental appearance and tooth color than men. In contrast study in Sweden found that men regarded dental appearance as more important than women [23] while other studies found that the differences were not significant $[5,7]$. Gender associated differences in satisfaction with dental appearance may require further investigations.

Increased labio-lingual inclination of the anterior teeth may have caused some patients to regard that their teeth as protruding, another factor that influenced patient satisfaction with general dental appearance. We found that, other tooth malalignments did not affect patient satisfaction with general appearance, although self-reported poorly aligned teeth and upper anterior crowding have been found to be associated with patients satisfaction $[3,27]$. These discrepancies highlighted the wide individual variation in appreciation of acceptable occlusal features. Individuals who perceived their profiles as being different from average were found more likely to be dissatisfied with their facial appearance [28]. Poor tooth alignment and crowding are among the most common malocclusion traits reported in the literature [29-31], which may explain our finding of a lack of association between patients' perceptions of having these traits and satisfaction with general dental appearance.

This study was based entirely on self-reports by patients through an interviewer guided questionnaire. We did not attempt to correlate patient self assessments of their dental problems and their dental records or to compare patients' desired aesthetic treatments and professional assessments of their needs. Furthermore, since the subjects of this study were patients who came to the dental clinic for treatment, they would be expected to be more aware and sensitive to their dental appearance.

\section{Conclusions}

Most patients in this study expressed dissatisfaction with their dental appearance. Dissatisfaction was more common in females than in males. Unhappiness with tooth color and feelings of having protruding teeth also had significant negative influences on patient satisfaction with their general dental appearance. The importance of tooth color was further supported by our finding that most patients would like to have their teeth whitened. These results provide useful indications of the potential demands for dental treatment, particularly aesthetic treatment. In addition, understanding patients' perceptions of their dental appearance is an important aspect of patient management which may assist dentists in planning treatments that are acceptable to the patients leading to higher levels of patient satisfaction.

\section{Acknowledgements}

The authors acknowledge the staff of the Hospital Universiti Sains Malaysia Dental Clinic, who facilitated the performance of this study.

\section{Authors' contributions}

MMTO contributed to the design of the study, analyzed the data and wrote the manuscript. NKS contributed to data analyses and interpretation, and revised the manuscript. $\mathrm{NH}$ contributed to data acquisition and data management. All authors read and approved the final manuscript.

\section{Competing interests}

The authors declare that they have no competing interests.

Received: 10 September 2010 Accepted: 23 February 2011 Published: 23 February 2011

\section{References}

1. Qualtrough A, Burke F: A look at dental esthetics. Quintessence International 1994, 25(1):7-14

2. Van der Geld P, Oosterveld P, Van Heck G, Kuijpers-Jagtman A: Smile attractiveness. Self-perception and influence on personality. The Angle Orthodontist 2007, 77(5):759-765.

3. Samorodnitzky-Naveh G, Geiger S, Levin L: Patients' satisfaction with dental esthetics. Journal of the American Dental Association 2007, 138(6):805-808.

4. Alkhatib M, Holt R, Bedi R: Prevalence of self-assessed tooth discolouration in the United Kingdom. Journal of Dentistry 2004, 32(7):561-566.

5. Xiao J, Zhou X, Zhu W, Zhang B, Li J, Xu X: The prevalence of tooth discolouration and the self-satisfaction with tooth colour in a Chinese urban population. Journal of Oral Rehabilitation 2007, 34(5):351-360.

6. Kershaw S, Newton J, Williams D: The influence of tooth colour on the perceptions of personal characteristics among female dental patients: comparisons of unmodified, decayed and 'whitened' teeth. British Dental Journal 2008, 204:E9.

7. Akarslan Z, Sadik B, Erten H, Karabulut E: Dental esthetic satisfaction, received and desired dental treatments for improvement of esthetics. Indian Journal of Dental Research 2009, 20(2):195-200.

8. Al-Omiri M, Karasneh J, Lynch E, Lamey P, Clifford T: Impacts of missing upper anterior teeth on daily living. International Dental Journal 2009, 59(3):127-132.

9. Gerritsen A, Sarita P, Witter D, Kreulen C, Mulder J, Creugers N: Esthetic perception of missing teeth among a group of Tanzanian adults. The International Journal of Prosthodontics 2008, 21(2):169-173. 
10. John M, Slade G, Szentpétery A, Setz J: Oral health-related quality of life in patients treated with fixed, removable, and complete dentures 1 month and 6 to 12 months after treatment. The International Journal of Prosthodontics 2004, 17(5):503-511.

11. Grossmann A, Hassel A, Schilling O, Lehmann F, Koob A, Rammelsberg P: Treatment with double crown-retained removable partial dentures and oral health-related quality of life in middle- and high-aged patients. The International Journal of Prosthodontics 2007, 20(6):576-578.

12. Chi J, Harkness M, Crowther P: A longitudinal study of orthodontic treatment need in Dunedin schoolchildren. New Zealand Dental Journal 2000, 96(423):4-9.

13. Manzanera D, Montiel-Company J, Almerich-Silla J, Gandía J: Orthodontic treatment need in Spanish schoolchildren: an epidemiological study using the Index of Orthodontic Treatment Need. European Journal of Orthodontics 2009, 31(2):180-183.

14. Esa R, Razak I, Allister J: Epidemiology of malocclusion and orthodontic treatment need of 12-13-year-old Malaysian schoolchildren. Community Dental Health 2001, 18(1):31-36.

15. Baubiniene D, Sidlauskas A, Miseviciene I: The need for orthodontic treatment among 10-11- and 14-15-year-old Lithuanian schoolchildren. Medicina (Kaunas) 2009, 45(10):814-821.

16. Sharma J: Epidemiology of malocclusions and assessment of orthodontic treatment need for the population of eastern Nepal. World Journal of Orthodontics 2009, 10(4):311-316.

17. Zhang M, McGrath C, Hägg U: The impact of malocclusion and its treatment on quality of life: a literature review. International Journal of Paediatric Dentistry 2006, 16(6):381-387.

18. Kiyak H: Does orthodontic treatment affect patients' quality of life? Journal of Dental Education 2008, 72(8):886-894.

19. Lemeshow S, Hosmer D, Klar J, Lwanga S: Adequacy of sample size in health studies Colchester, England: John Wiley \& Sons; 1990.

20. Vallittu P, Vallittu A, Lassila V: Dental aesthetics-a survey of attitudes in different groups of patients. Journal of Dentistry 1996, 24(5):335-338.

21. Alkhatib M, Holt R, Bedi R: Age and perception of dental appearance and tooth colour. Gerodontology 2005, 22(1):32-36.

22. Odioso L, Gibb R, Gerlach R: Impact of demographic, behavioral, and dental care utilization parameters on tooth color and personal satisfaction. Compendium of Continuing Education in Dentistry 2000, 29: S35-41.

23. Carlsson G, Johansson A, Johansson A, Ordell S, Ekbäck G, Unell L: Attitudes toward dental appearance in 50- and 60-Year-old subjects living in Sweden. Journal of Esthetic and Restorative Dentistry 2008, 20(1):46-55.

24. Hassel A, Wegener I, Rolko C, Nitschke I: Self-rating of satisfaction with dental appearance in an elderly German population. International Dental Journal 2008, 58(2):98-102.

25. Joiner A: Tooth colour: a review of the literature. Journal of Dentistry 2004 32(Suppl 1):3-12.

26. Höfel $L$, Lange $M$, Jacobsen $T$ : Beauty and the teeth: perception of tooth color and its influence on the overall judgment of facial attractiveness. The International Journal of Periodontics \& Restorative Dentistry 2007, 27(4):349-357.

27. Marques L, Filogônio C, Filogônio C, Pereira L, Pordeus I, Paiva S, Ramos Jorge $M$ : Aesthetic impact of malocclusion in the daily living of Brazilian adolescents. Journal of Orthodontics 2009, 36(3):152-159.

28. Tufekci $E$, Jahangiri A, Lindauer S: Perception of profile among laypeople, dental students and orthodontic patients. The Angle Orthodontist 2008, 78(6):983-987.

29. Jonsson T, Arnlaugsson S, Karlsson K, Ragnarsson B, Arnarson E, Magnusson T: Orthodontic treatment experience and prevalence of malocclusion traits in an Icelandic adult population. American Journal of Orthodontics and Dentofacial Orthopedics 2007, 131(1):8.e11-18.e18.

30. Onyeaso C: Prevalence of malocclusion among adolescents in Ibadan, Nigeria. American Journal of Orthodontics and Dentofacial Orthopedics 2004, 126(5):604-607.

31. Borzabadi-Farahani A, Borzabadi-Farahani A, Eslamipour F: Malocclusion and occlusal traits in an urban Iranian population. An epidemiological study of 11- to 14-year-old children. European Journal of Orthodontics 2009, 31(5):477-484.

\section{Pre-publication history}

The pre-publication history for this paper can be accessed here: http://www.biomedcentral.com/1472-6831/11/6/prepub

doi:10.1186/1472-6831-11-6

Cite this article as: Tin-Oo et al:: Factors influencing patient satisfaction with dental appearance and treatments they desire to improve aesthetics. BMC Oral Health 2011 11:6.

\section{Submit your next manuscript to BioMed Central and take full advantage of:}

- Convenient online submission

- Thorough peer review

- No space constraints or color figure charges

- Immediate publication on acceptance

- Inclusion in PubMed, CAS, Scopus and Google Scholar

- Research which is freely available for redistribution

Submit your manuscript at www.biomedcentral.com/submit
Biomed Central 